\title{
Synthesis of highly dispersed chromium diboride powder by means of boron carbide reduction using nanofiber carbon
}

\author{
V.I. Chushenkov†, Y.L. Krutskii, T.S. Kvashina, Y.P. Steksova \\ †chushenkov.vladislav@mail.ru
}

Novosibirsk state technical university, 20 Karl Marx avenue, 630073, Novosibirsk, Russia

\begin{abstract}
The article describes the synthesis of highly dispersed powder of chromium diboride $\mathrm{CrB}_{2}$ using nanofiber carbon in the process of boron carbide reduction. This compound is a refractory material with melting point of $2200^{\circ} \mathrm{C}$. Due to its chemical and physical properties, chromium diboride is widely used in different fields of industry. Chromium oxide (III) $\mathrm{Cr}_{2} \mathrm{O}_{3}$, boron carbide $\mathrm{B}_{4} \mathrm{C}$ and nanofiber carbon $\mathrm{C}$ were used as initial reagents. The synthesis was conducted by the use of an induction furnace of a melting pot type in a protective atmosphere of argon at temperatures of 1300,1500 and $1700^{\circ} \mathrm{C}$. Using X-ray phase analysis, atomic emission spectroscopy with inductively coupled plasma, scanning electron microscopy and synchronized thermal TG-DSC analysis general properties and characteristics of the materials obtained were determined. Particle size distribution studies have been also carried out and it has been found that the average size of chromium diboride powder was $7.95 \mu \mathrm{m}$. It has been found that the sample of chromium diboride obtained resists oxidation under higher temperatures $\left(1000^{\circ} \mathrm{C}\right)$. The paper also deals with the problem of targeted planning of chromium diboride synthesis depending on different experimental conditions. By the use of targeted experiment planning method, the effects of such parameters as synthesis temperature, time of stirring of the initial batch, as well as carbon reducing agent which significantly affects the synthesis process were estimated. It has been found that optimum synthesis conditions consist in an activation of batch in a ball mill with acceleration of $10 \mathrm{~g}$ for 5 minutes and a synthesis at $1700^{\circ} \mathrm{C}$ for 20 minutes.
\end{abstract}

Keywords: high-melting compounds, nanofiber carbon, chromium diboride synthesis, boron carbide reducing reaction.

\section{Синтез высокодисперсного порошка диборида хрома с использованием нановолокнистого углерода методом карбидоборного восстановления}

\author{
Чушенков В.И. ${ }^{\dagger}$ Крутский Ю.Л., Квашина Т.С., Стексова Ю.П. \\ †chushenkov.vladislav@mail.ru
}

Новосибирский государственный технический университет, пр-т Карла Маркса 20, 630073, Новосибирск, Россия

В данной работе описан процесс получения высокодисперсного порошка диборида хрома $\mathrm{CrB}_{2}$ с использованием нановолокнистого углерода карбидоборным методом. Данное соединение является тугоплавким, его температура плавления составляет $2200^{\circ} \mathrm{C}$. За счет своих физико-химических свойств диборид хрома получил широкое применение в промышленности. В качестве исходных реагентов использовали оксид хрома (III) $\mathrm{Cr}_{2} \mathrm{O}_{3}$, карбид бора $\mathrm{B}_{4} \mathrm{C}$ и нановолокнистый углерод С. Синтез проводили в индукционной печи тигельного типа в защитной среде аргона при температурах 1300, 1500 и $1700^{\circ} \mathrm{C}$. С помощью методов рентгенофазового анализа, атомно-эмиссионной спектроскопии с индуктивно связанной плазмой, растровой электронной микроскопии, синхронного термического ТГ-ДСК-анализа определили основные свойства и характеристики полученных образцов. Выполнены гранулометрические исследования, в ходе которых определили средний размер частиц полученного порошка диборида хрома, который составил 7,95 мкм. Установлено, что полученный образец диборида хрома эффективно сопротивляется окислению при повышенных температурах $\left(1000^{\circ} \mathrm{C}\right)$. Также в данной статье рассмотрены вопросы направленного планирования процесса синтеза диборида хрома в зависимости от различных условий проведения эксперимента. Методом направленного планирования эксперимента было оценено влияние на процесс синтеза таких параметров, как температура синтеза, время перемешивания исходной шихты, а также типа углеродного восстановителя, который в значительной степени влияет на процесс синтеза. Оптимальный режим синтеза: активация шихты в шаровой мельнице при ускорении в $10 \mathrm{~g}$ в течении 5 мин, синтез при температуре $1700^{\circ} \mathrm{C}$ в течение 20 мин.

Ключевые слова: тугоплавкие соединения, нановолокнистый углерод, синтез диборида хрома, карбидоборное восстановление. 


\section{1. Введение}

Соединения металлов с бором - бориды - представляют собой очень важный и обширный класс неорганических соединений, отличающихся тугоплавкостью, высокой химической стойкостью в различных агрессивных средах, а также высокими показателями электро- и теплопроводности. Одним из наиболее важных представителей боридов является диборид хрома $\mathrm{CrB}_{2}$. Его $T_{\text {плав }}=2200^{\circ} \mathrm{C}$, он устойчив к воздействию $\mathrm{NaOH}$, $\mathrm{HNO}_{3 \text { (конц) }}$ окислению кислородом при высоких темпеpaтурах [1].

Стоит отметить, что тугоплавкие соединения все чаще находят свое применение в различных отраслях промышленности, включая аэрокосмическую, химическую, металлургическую и т.д., к ним относится и диборид хрома.

Существует достаточно большое количество способов синтеза вышеуказанного соединения, к ним относят: магнийтермический метод, электрохимический синтез, боротермический метод, карботермическое восстановление, синтез из элементов и т.д. Наиболее перспективным считается метод, получивший название карбидоборное восстановление. Также данный метод синтеза диборида хрома наиболее перспективен для организации промышленного производства [2].

Стоит также отметить, что в Новосибирском государственном техническом университете на кафедре химии и химической технологии проводят реакции синтеза водорода методом селективного каталитического пиролиза легких углеводородов. Одним из продуктов процесса является нановолокнистый углерод (НВУ), обладающий рядом уникальных свойств, по сравнению с обычным углеродным материалом (сажей). В частности, он имеет высокое значение удельной поверхности ( 200 м²/г) [3]. На рисунке 1 показаны снимки просвечивающей электронной микроскопии НВУ и сажи.

Цель данного исследования заключалась в синтезе диборида хрома методом карбидоборного восстановления с использованием НВУ. Новизна данного исследования состоит в том, что применение НВУ при синтезе диборида хрома ранее изучено не было.

\section{2. Методика проведения экспериментов}

В качестве исходных реагентов для реакции синтеза также выступили высокодисперсные порошки карбида бора $\mathrm{B}_{4} \mathrm{C}$ [4] и оксида хрома (III) $\mathrm{Cr}_{2} \mathrm{O}_{3}$ с размером частиц менее 1 мкм. Шихту для карбидоборного синтеза $\mathrm{CrB}_{2}$ готовили в соответствии со стехиометрией для реакции:

$$
\mathrm{Cr}_{2} \mathrm{O}_{3}+\mathrm{B}_{4} \mathrm{C}+2 \mathrm{C}=2 \mathrm{CrB}_{2}+3 \mathrm{CO} \uparrow,
$$

Исходные реагенты для гомогенизации шихты были просеяны через сито с размером в 100 мкм. Полученную шихту засыпали в тигель из стеклоуглерода, далее тигель помещали в кварцевый химический реактор, который, в свою очередь, помещали в индукционную печь тигельного типа. Для того чтобы избежать нежелательного азотирования карбида бора при высоких температурах синтез диборида хрома проводили в среде аргона.

Синтез проводили при температурах $1300^{\circ} \mathrm{C}$, $1500^{\circ} \mathrm{C}$ и $1700^{\circ} \mathrm{C}$, время выдержки в печи составляло 20 минут.

Как можно заметить из реакции (1) процесс синтеза диборида хрома сопровождается выделением газа $\mathrm{CO}$, что в свою очередь характеризуется убылью массы. Убыль массы напрямую характеризует полноту прохождения реакции синтеза. Данный параметр определяли путем взвешивания полученных образцов, после чего осуществляли перевод убыли массы в \%.

Продукты реакций подвергали рентгенофазовому анализу на дифрактометре ДРОН-3 с использованием

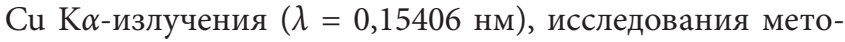
дом атомно-эмиссионной спектроскопии с индуктивно связанно плазмой проводили на приборе IRIS Advantage (Thermo Jarrel Ash corporation, USA).

Микроструктуру исследовали на растровом электронном микроскопе Hitachi S - 3400N, оборудованного приставкой для энергодисперсионного анализа производства фирмы «Oxford Instruments». Микрофотографии поверхности образцов были получены в режиме низкого вакуума детектором обратно-рассеянных электронов.

Термоокислительную стабильность диборида хрома определяли с использованием прибора синхронного термического анализа NETZSCH STA 449 C Jupiter. В ходе анализа проводили окисление образца в атмосфере кислорода при нагревании до температуры $1000^{\circ} \mathrm{C}$ со скоростью 10 град/мин и выдерживании в течение 3 часов.

Гранулометрический анализ выполняли на автоматическом лазерном анализаторе частиц Microsizer 201.

\section{3. Результаты экспериментов и их обсуждение}

Согласно реакции (1) процесс синтеза диборида хрома сопровождается выделением газа СО. Экспериментальная убыль массы (за счет выделения СО) после синтеза при $1300^{\circ} \mathrm{C}, 1500^{\circ} \mathrm{C}$ и $1700^{\circ} \mathrm{C}$ составила $24,41 \%$; $31,12 \%$; и $36,08 \%$, соответственно, в то время как расчетная составила $36,2 \%$. Экспериментальная убыль массы при температуре $1700^{\circ} \mathrm{C}$ очень близка к расчетной, что свидетельствует о практически полном протекании синтеза $\mathrm{CrB}_{2}$ при данной температуре.

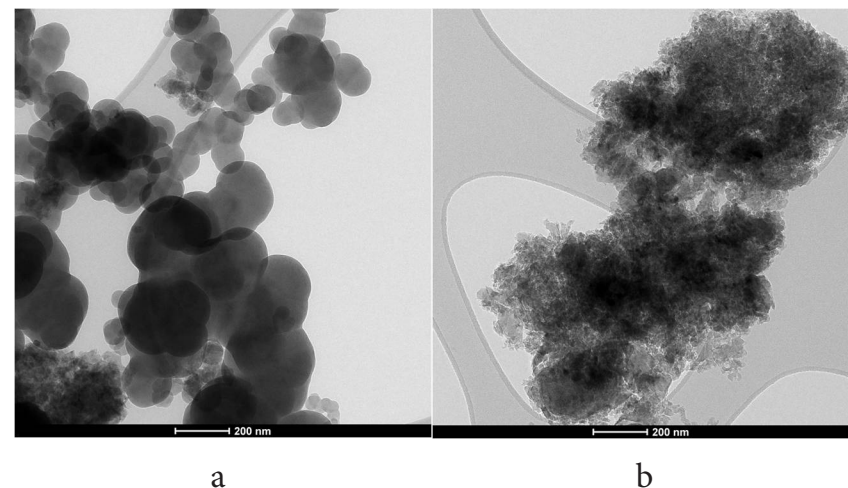

Рис. 1. Снимки просвечивающей электронной микроскопии углеродных материалов а) сажа; b) НВУ.

Fig. 1. TEM pictures of the carbon materials a) carbon black; b) NFC. 
По данным рентгенофазового анализа практически чистый однофазный продукт был получен при температуре $1700^{\circ} \mathrm{C}$ (рис. 2).

На дифрактограммах образцов, полученных при температуре ниже $1700^{\circ} \mathrm{C}$, наблюдаются пики $\mathrm{CrB}, \mathrm{Cr}_{3} \mathrm{~B}_{4}$ и $\mathrm{CrB}_{2}$. Это говорит о том, что, предположительно, процесс образования диборида хрома проходит через постепенное образование фаз $\mathrm{Cr}_{2} \mathrm{~B} \rightarrow \mathrm{Cr}_{5} \mathrm{~B}_{3} \rightarrow \mathrm{CrB} \rightarrow \mathrm{Cr}_{3} \mathrm{~B}_{4} \rightarrow \mathrm{CrB}_{2}$. Поскольку наиболее полный синтез прошел при $1700^{\circ} \mathrm{C}$, дальнейшие исследования провели только на этом образце.

По данным растровой электронной микроскопии частицы диборида хрома агрегированы, имеют удлиненную форму с округлыми краями. Диаметр частиц составляет около 2 мкм, длина -4 мкм (рис. 3 ).

Необходимо отметить, что растровая электронная микроскопия предназначена для непосредственной оценки формы и морфологии полученных образцов, а данные по размерам частиц являются приблизительными и несут лишь ознакомительную функцию. Для точной оценки размеров частиц применяется метод гранулометрического анализа.

Выполнив гранулометрический анализ (рис. 4) и расчет по методике [5], используя геометрический метод моментов, выяснили, что средний размер частиц составил 7,95 мкм. Рассчитанные величины стандартного отклонения и коэффициента асимметрии показали,

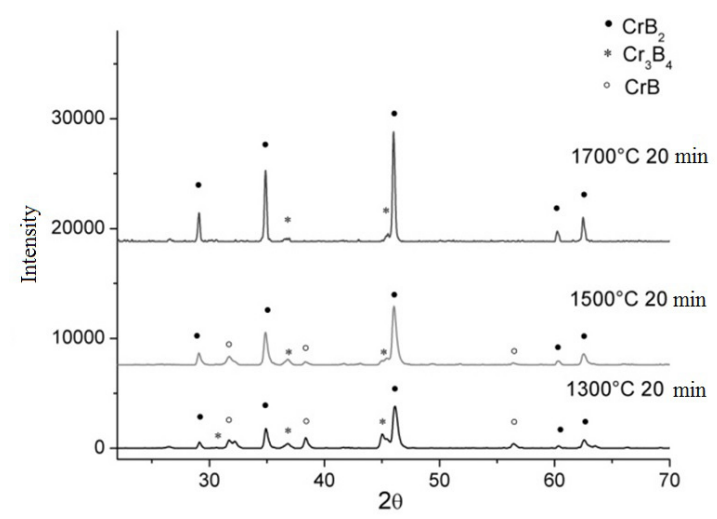

Рис. 2. Дифрактограммы образцов диборида хрома после синтеза при различных температурах.

Fig. 2. The diffraction patterns of samples of the chromium diboride after synthesis under the different temperatures.

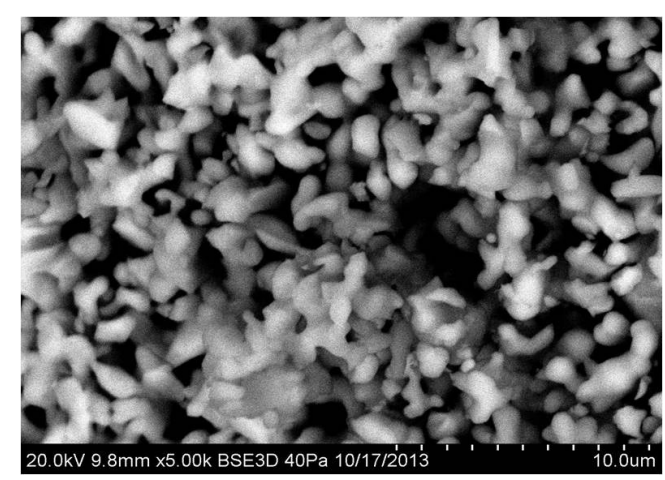

Рис. 3. Микроструктура образца диборида хрома после синтеза при $1700^{\circ} \mathrm{C}$. Растровая электронная микроскопия.

Fig. 3. The microstructure of the chromium diboride sample after synthesis at $1700^{\circ} \mathrm{C}$. Scanning electron microscopy. что частицы имеют широкий диапазон дисперсности, а кривая распределения симметрична. Также по результатам седиментационного анализа установлено, что значение $\mathrm{D}_{50}$ - средний размер 50\% частиц - для диборида хрома составляет 8,29 мкм.

Согласно результатам атомно-эмиссионной спектрометрии с индуктивно связанной плазмой содержание хрома в образце составляет 68,06\%, содержание бора $31,07 \%$, что близко к расчётным значениям. В образце обнаружили примеси других элементов с общим содержанием не более $1,5 \%$.

Как было отмечено ранее, диборид хрома очень устойчив к окислению в агрессивных средах, в частности, к окислению кислородом [1], поэтому было решено провести термический анализ полученного образца $\mathrm{CrB}_{2}$. Стоит отметить, что при окислении всех боридов при температуре $\sim 450^{\circ} \mathrm{C}$ образуется бороксидная пленка $\mathrm{B}_{2} \mathrm{O}_{3}$, которая препятствует дальнейшему окислению, что и обусловливает высокую коррозионную стойкость диборида хрома [6]. Заметное окисление боридов наблюдается лишь при температуре $\sim 1200^{\circ} \mathrm{C}$, когда увеличивается летучесть $\mathrm{B}_{2} \mathrm{O}_{3}$.

По результатам совместного ТГ-ДСК термического анализа образец диборида хрома, синтезированный при $1700^{\circ} \mathrm{C}$, начинает окисляться при температуре $498^{\circ} \mathrm{C}$, а при выдержке при температуре $1000^{\circ} \mathrm{C}$ в течение 3 часов он окисляется на $44 \%$ (рис. 5). Процесс окисления характеризуется тремя пиками тепловыделения. Максимальное тепловыделение наблюдается при температуре $719^{\circ} \mathrm{C}$, второй и третий пики образуются при температуpax $882^{\circ} \mathrm{C}$ и $999^{\circ} \mathrm{C}$.

Для того чтобы рационализировать процесс синтеза и выяснить, какие основные параметры влияют на него, было решено провести оптимизацию процесса синтеза диборида хрома методом направленного планирования эксперимента. Все необходимые исследования по направленному планированию проводили в соответствии с методиками, описанными в источнике [7].

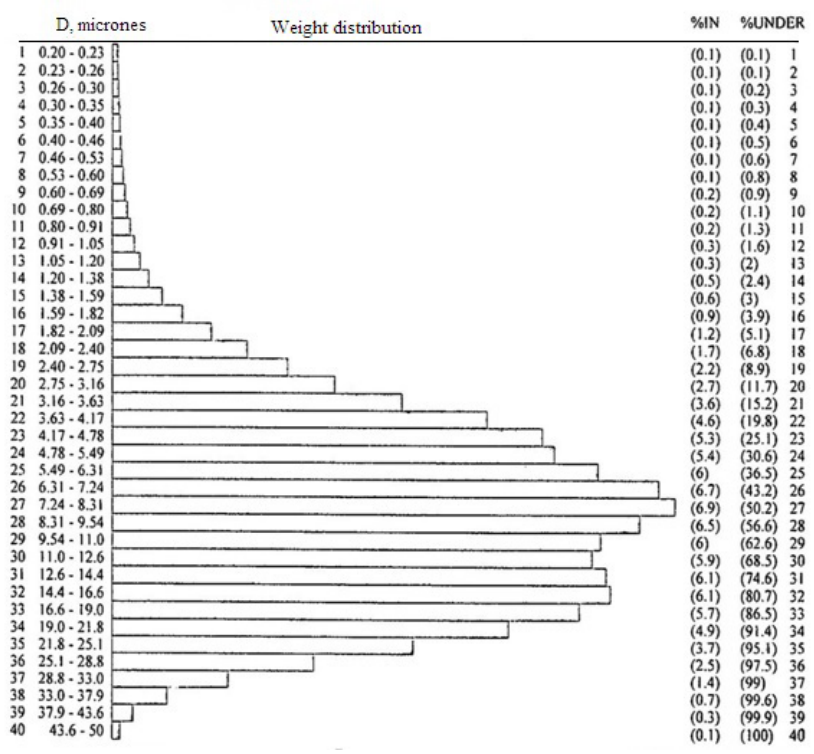

Рис. 4. Гранулометрический анализ. Распределение частиц по размерам.

Fig. 4. Granulometric analysis. The size distribution of the particles. 
Поскольку в шихту входят три компонента, перемешивание может оказать достаточное влияние на гомогенность шихты. Для перемешивания и механической активации исходной смеси была использована шаровая планетарная мельница (ШПМ).

После перемешивания в ШПМ шихту не просеивали через сито, помещали в печь и нагревали до температур $1500^{\circ} \mathrm{C}$ и $1700^{\circ} \mathrm{C}$ в среде аргона; время выдержки при указанных температурах составляло 25 минут. В качестве факторов влияния были выбраны температура, время перемешивания и ускорение шаров в мельнице. В качестве параметра оптимизации выбрали количество образующихся фаз и изменение массы шихты в \%.

Проведя необходимые эксперименты (4 опыта) и выполнив рентгенофазовый анализ и энергодисперсионную рентгеновскую спектроскопию полученных образцов установили, что порошки, полученные при температуре $1500^{\circ} \mathrm{C}$, содержат другие боридные фазы, тогда как после синтеза при температуре $1700^{\circ} \mathrm{C}$ наблюдается преимущественно фаза диборид хрома. После выполнения дополнительных расчетов и составления уравнений регрессии было установлено, что основным фактором, влияющим на качество полученных порошков, является температура. Время перемешивания и ускорение шаров в ШПМ влияют в меньшей степени, продолжительность перемешивания не влияет на результаты эксперимента.

Также в рамках направленного планирования эксперимента были проведены исследования крутого восхождения при уменьшении составляющей градиента (коэффициентов уравнений регрессии) в 10 раз [7]. Выполнив необходимые расчеты и эксперименты, также было установлено, что основным влияющим фактором является именно температура. Обнаружено, что при температурах синтеза свыше $1800^{\circ} \mathrm{C}$ конечный продукт синтеза полностью спекается. По результатам планирования эксперимента оптимальными условиями для синтеза порошка диборида хрома являются следующие: температура синтеза $1700^{\circ} \mathrm{C}$, время выдержки 20 мин, активация шихты при ускорении в $10 \mathrm{~g}$ в течении 5 мин.

Для выяснения эффективности влияния типа углеродного восстановителя на синтез диборида хрома

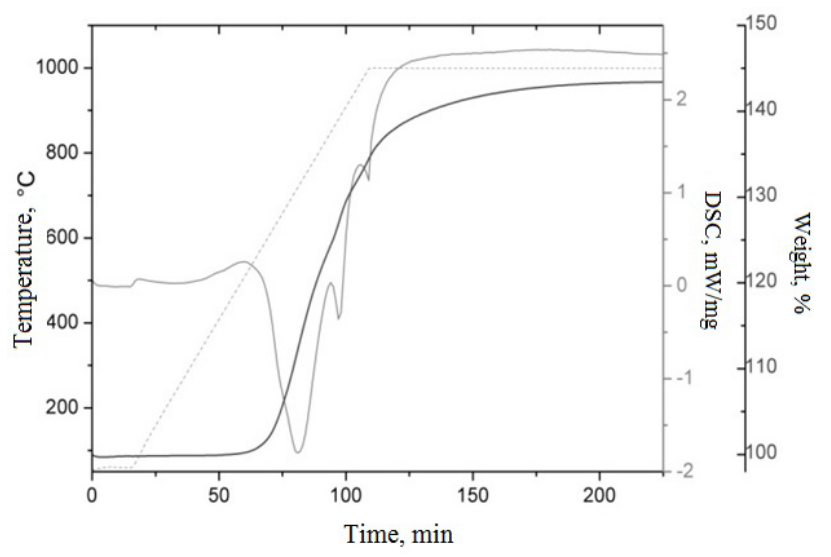

Рис. 5. ТГ-ДСК кривые образца диборида хрома, синтезированного при $1700^{\circ} \mathrm{C}$.

Fig. 5. TG-DSC curves of samples of the chromium diboride synthesized at $1700^{\circ} \mathrm{C}$. провели отжиг шихты при температуре $1700^{\circ} \mathrm{C}$ с использованием сажи. Результат рентгенофазового анализа образца, синтезированного с применением сажи, представлен на рис. 6.

Продукт, полученный синтезом с сажей, содержит не только фазы $\mathrm{CrB}_{2}$ и $\mathrm{Cr}_{3} \mathrm{~B}_{4}$, но и не прореагировавший углерод, чего не наблюдалось при синтезе с НВУ. Это свидетельствует о том, что тип углеродного материала в значительной степени влияет на процесс синтеза $\mathrm{CrB}_{2}$.

\section{4. Заключение}

После проведения синтеза диборида хрома при температурах $1300^{\circ} \mathrm{C}, 1500^{\circ} \mathrm{C}$ и $1700^{\circ} \mathrm{C}$ установили, что экспериментальная убыль массы шихты соответствует расчетному значению только при температуре синтеза $1700^{\circ} \mathrm{C}$ и равна $36,08 \%$. В образце полученном при $1700^{\circ} \mathrm{C}$ соотношение бора и хрома также близко к расчетному, а содержание примесей не превышает $1,5 \%$. При температурах $1300^{\circ} \mathrm{C}$ и $1500^{\circ} \mathrm{C}$ образуются в значительных количествах другие боридные фазы $\left(\mathrm{CrB}, \mathrm{Cr}_{3} \mathrm{~B}_{4}\right)$, что свидетельствует о том, что при этих температурах синтез диборида хрома не проходит до конца.

Средний размер частиц порошка диборида хрома, полученного при температуре $1700^{\circ} \mathrm{C}$, составляет 7,95 мкм.

Образец диборида хрома начинает окисляться при температуре $\sim 498^{\circ} \mathrm{C}$, при выдержке при температуре $1000^{\circ} \mathrm{C}$ в течение 3 часов окисляется на $44 \%$, что свидетельствует о его высокой коррозионной устойчивости.

Оптимальными условиями для синтеза высокодисперсного порошка $\mathrm{CrB}_{2}$ являются: температура $1700^{\circ} \mathrm{C}$, время выдержки 20 минут, активация шихты при ускорении в ШПМ $10 \mathrm{~g}$ в течении 5 минут. Тип углеродного материала в значительной степени влияет на процесс синтеза.

Подводя общий итог необходимо отметить, что НВУ является очень важным и перспективным материалом для синтеза высокодисперсного, практически чистого порошка $\mathrm{CrB}_{2}$ карбидоборным методом в одну стадию.

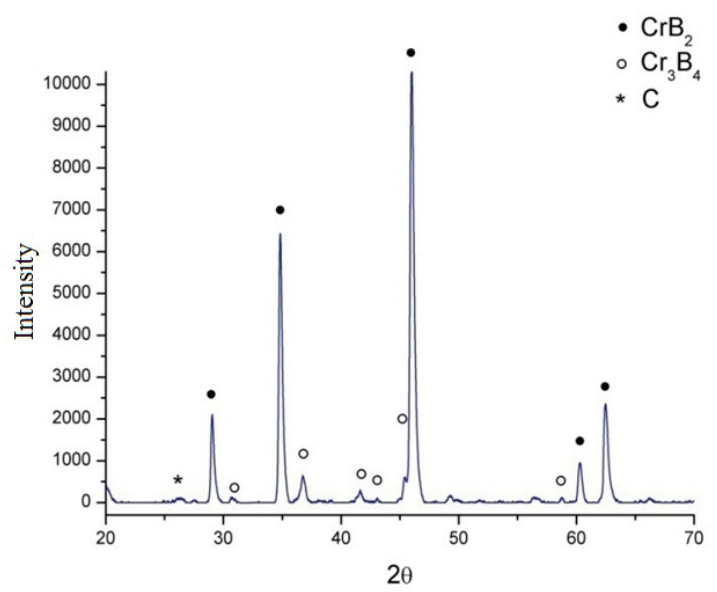

Рис. 6. Дифрактограмма образца, синтезированного при температуре $1700^{\circ} \mathrm{C}$ с применением сажи.

Fig. 6. The diffraction patterns of sample synthesized at $1700^{\circ} \mathrm{C}$ with carbon black application. 


\section{Литература/References}

1. T.Y. Kosolapova. Properties, production and application of high-melting compounds. Directory issue. Moscow. Metallurgy. (1986) 928 p. (in Russian) [Т. Я. Косолапова. Свойства, получение и применение тугоплавких соединений. Справочное издание. Москва. Металлургия. 1986. 928 с.]

2. J.K. Sonber, TSR Ch Murthy, C Subramanian. International Journal of Refractory Metals and Hard Materials. 27 (5), p. 912 (2009).

3. G.G. Kuvshinov, Yu.I. Mogilnykh, D.G. Kuvshinov, D. Yu. Yermakov, M.A. Yermakova, A.N. Salanov, N.A. Rudina. Carbon. 37 (8), p. 1239 (1999). DOI: $10.1016 /$ S0008-6223 (98) 00320-0.
4. Y.L. Krutskii, A.G. Bannov, V.V. Sokolov. Nanotechnologies in Russia. 8 (3-4), p. 191 (2013). DOI: 10.1134/S1995078013020109

5. S.J. Blot, K. Pye. Earth Surf. Process. Landforms 26, 1237 - 1248 (2001). DOI:10.1002/esp.261.

6. R.F. Woitovich, E.A. Pugach. The oxidation of highmelting compounds. Directory. Moscow. Metallurgy. (1978) 112 p. (in Russian) [Р. Ф. Войтович, Э. А. Пугач. Окисление тугоплавких соединений. Справочник. Москва.Металлургия. 1978. 112 с.]

7. J.P. Adler, E. V. Markova, J. V. Granovskii. An experiment planning in search for optimal conditions. Moscow. Science. (1976) 279 p. (in Russian) [Ю.П. Адлер, Е.В. Маркова, Ю.В. Грановский. Планирование эксперимента при поиске оптимальных условий. Москва. Изд-во Наука. 1976. 279 с.] 